\title{
A NOTE ON A THEOREM OF BORWEIN, BORWEIN, FEE AND GIRGENSOHN
}

\author{
SHLOMO REISNER
}

Abstract. A simple application of a theorem of [1] shows that the product of the volume of the unit ball of $\ell_{p}^{n}$ by the volume of the unit ball of its dual space is increasing for $1 \leqslant p \leqslant 2$.

Mathematics subject classification (2000): 52A22, 26B25, 52A38, 33B15.

Key words and phrases: Normed-spaces, unit-balls, volume-product-inequalities.

\section{REFERENCES}

[1] D. Borwein, J. Borwein, G. FeE And R. Girgensohn, Refined convexity and special cases of the Blaschke-Santalò inequality, Mathematical Inequalities \& Applications 4 (2001), 631-638.

[2] S. REISNER, Zonoids with minimal volume-product, Math. Zeitschrift 192 (1986), 339-346. 